\title{
EFEKTIFITAS MEDIA PEMBELAJARAN TEMATIK INTEGRATIF BERBASIS BUDAYA LOKAL MASYARAKAT PATI MELALUI PENDEKATAN SCIENTIFIC
}

\author{
Yuni Ratnasari, Santoso \\ yunaiuns@yahoo.com, sentosa_mpd@yahoo.co.id \\ Pendidikan Guru Sekolah Dasar FKIP UMK
}

\begin{abstract}
Abtract
Learning Effective and efficient process is carried Posted Demands Should teachers on application of Curriculum 2013. Teachers and Students Still Not using an media about cultural life community with a maximum, so that cognitive achievement students still low. One solution is to implement learning should teacher with thematic integrative Based Learning Media Local culture on community Pati with scientific approach. The research goal is to know the effectiveness of the Learning husband with thematic integrative Based Learning Media Local culture society Pati with scientifik approach.

This study uses research and development. The research was conducted in three schools in the district Pati there are SDN Blaru 02, SDN Sukoharjo 01 and SDN Bakaran Wetan 01. The research was conducted starting with a preliminary study at all schools and then proceed to the stage of media development. Media developed in three schools tested in the study. The results of trials in the analysis are then based on the analysis of media and instrument repair. Media that has been fixed into the final media back then implemented in three schools of learning in the study.

The results showed a very effective learning with instructional media thematic integrative community based local culture through the Pati district scientific approach.
\end{abstract}

Keywords: Effectiveness of Learning, Learning Media Thematic integrative, local Cultural Society Pati, Scientific Approach.

\begin{abstract}
Abstrak
Pembelajaran yang efektif dan efisien merupakan tuntutan yang harus dilakukan oleh guru pada penerapan kurikulum 2013. Guru dan siswa masih belum mengunakan media ajar yang ada dalam kehidupan budaya masyarakat dengan maksimal, sehingga prestasi kognitif siswa masih rendah. Salah satu solusinya adalah guru harus melaksanakan pembelajaran dengan media pembelajaran tematik integrative berbasis budaya lokal pada masyarakat Pati dengan pendekatan scientific. Tujuan penelitian ini adalah mengetahui efektifitas pembelajaran dengan media pembelajaran tematik integrative berbasis budaya lokal masyarakat Pati dengan pendekatan scientifik.

Penelitian ini menggunakan metode research and development. Penelitian dilaksanakan di tiga sekolah di kabupaten Pati yaitu SDN Blaru 02, SDN Sukoharjo 01 dan SDN Bakaran wetan 01. Penelitian dilaksanakan diawali dengan studi pendahuluan di seluruh sekolah kemudian dilanjutkan dengan tahap pengembangan media. Media yang dikembangkan di uji cobakan di tiga sekolah penelitian. Hasil uji coba di analisis kemudian berdasarkan hasil analisis media dan instrument diperbaiki. Media yang telah diperbaiki menjadi media final kemudian di implementasikan kembali dalam pembelajaran di tiga sekolah penelitian.
\end{abstract}


Hasil penelitian menunjukkan pembelajaran sangat efektif dengan media pembelajaran tematik integrative berbasis budaya lokal masyarakat kabupaten Pati melalui pendekatan scientifik.

Kata Kunci: Efektifitas Pembelajaran, Media Pembelajaran Tematik Integratif, Budaya lokal Masyarakat Pati, Pendekatan Scientifik

\section{PENDAHULUAN}

Dinamika yang terjadi pada dunia pendidikan dasar adalah sering mengalami perubahan kurikulum. Perubahan kurikulum yang kurang didukung adanya perencanaan yang baik membuat guru dan siswa menjadi resah. Guru masih belum menguasai penerapan model pembelajaran yang diharapkan pada kurikulum 2013. Hal ini berdampak pada proses pembelajaran yang tidak efektif dan hasil belajar siswa yang menurun.

Secara umum belajar merupakan suatu aktivitas fisik maupun mental, yang berlangsung melalui pengalaman interaksi aktif dengan lingkungan, yang menghasilkan sejumlah perubahan tingkah laku dalam pengetahuan, pemahaman dan keterampilan. Penerapan kurikulum 2013 melalui pendekatan scientific meruapakan salah satu pembelajaran yang menekankan pada kemampuan siswa.

Pembelajaran melalui pendekatan saintifik adalah proses pembelajaran yang dirancang sedemikian rupa agar peserta didik secara aktif mengonstruksi konsep, hukum atau prinsip melalui tahapan-tahapan mengamati (untuk mengidentifikasi atau menemukan masalah), merumuskan masalah, mengajukan atau merumuskan hipotesis, mengumpulkan data dengan berbagai teknik, menganalisis data, menarik kesimpulan dan mengomunikasikan konsep, hukum atau prinsip yang ditemukan.
Untuk mewujudkan pembelajaran interaktik dan kontekstual maka pembelajaran berbasis budaya lokal merupakan salah satu hal bisa dilakukan untuk mewujudkan pembelajaran yang efektif dan efisien. Kabupaten Pati merupakan salah satu kota yang memiliki budaya lokal yang unik dan kreatif, diantaraya Batik Bakaran, Pengrajin Kuningan, Nelayan, Kuliner Soto Kemiri, Ketoprak, dll. Keanekaragaman budaya menjadi ciri khas masing-masing daerah, inilah yang mendasari untuk mengembangkan media pembelajaran yang berbasis budaya lokal. Pengembangan media pembelajaran ini diharapkan dapat memperlancar penerapan kurikulum 2013 yang masih dianggap membingungkan bagi sebagian guru sekolah dasar.

Brooks \& Brooks percaya bahwa pendekatan pembelajaran berbasis budaya dapat memberikan kesempatan kepada peserta didik untuk menciptakan makna dan mencapai pemahaman terpadu atas informasi keilmuan yang diperolehnya, serta penerapan informasi keilmuan tersebut dalam konteks permasalahan komunitas budayanya (Sutarno : 2004).

Era global membuat masyarakat menjadi kurang memiliki pemahaman yang baik terhadap budaya lokal yang ada di Kabupaten Pati. Siswa sebagai salah satu komponen yang ada dalam masyarakat budaya Pati diharapkan memiliki pemahaman dan merasa memiliki akan budaya masyarakatnya. Salah satu cara untuk menanamkan 
kemampuan siswa pada budaya lokal, maka kurikulum 2013 memiliki sinergi dengan budaya lokal yang ada. Budaya lokal bisa dijadikan sebagai sarana pembelajaran untuk meningkatkan pemahaman dan pengetahuan pada siswa terhadap muatan yang diajarkan pada siswa pada IPA dan PPKn.

Sub tema pekerjaanku pada muatan IPA dan PPKn bisa dikembangkan dalam pembelajaran tematik integrative dengan pendekatan scientific pada siswa di Kabupaten Pati. Tujuan penelitian ini adalah mengetahui efektifitas pembelajaran dengan media pembelajaran tematik integrative berbasis budaya lokal masyarakat Pati dengan pendekatan scientifik.

\section{METODE PENELITIAN}

\begin{abstract}
Penelitian ini menggunakan metode research and development (penelitian dan pengembangan) sebagaimana dikemukakan oleh Borg dan Gall (1989:784). Menurut Borg dan Gall dalam implementasi penelitian ada sepuluh langkah yang harus dilakukan. Penelitian dan pengembangan produk, peralatan dan model bergantung pada suatu variasi teknik kualitatif, antara lain studi kasus, wawancara, review dokumen, dan observasi (Prof. Dr. Emzir, M.Pd, 2011:260).
\end{abstract}

Penelitian ini memodifikasi 10 langkah penelitian Borg dan Gall menjadi tiga hapan yaitu: 1) studi pendahuluan, meliputi studi pustaka, studi lapangan dan ananlisis budaya lokal. 2) tahap pengembangan media, meliputi membuat media awal, uji coba media, menganalisis hasil ujicoba, memperbaiki media menjadi media final. 3) tahap validasi media, meliputi implementasi media dalam pembelajaran dan media teruji.

Penelitian ini dilaksanakan di SD Kabupaten Pati khusunya SDN
Bakaran Wetan 01 Juwana, SDN Sukoharjo 01 Margorejo dan SDN Blaru 02 Pati Kota dengan mengujicobakan media pembelajaran tematik integratif berbasis budaya lokal masyarakat sampai pada implementasinya. Sekolah tersebut tersebar dari tiga kecamatan yang diambil secara random sampling sederhana yang akan dijadikan penelitian. Harapannya ketiga sekolah dapat mewakili sekolah lainnya.

Prosedur penelitian dan pengembangan pada penelitian ini dapat dijelaskan seperti gambar 1 . berikut.

Teknik pengumpulan data pada penelitian ini dilakukan dengan melakukan observasi aktivitas guru dan siswa, tes evaluasi, angket respon guru dan siswa dan dokumentasi.

\section{HASIL DAN PEMBAHASAN}

Penelitian ini dilaksanakan
dengan tahapan meliputi tahap perijinan, tahap analisis kebutuhan, tahap pengembangan produk, tahap uji coba produk, tahap perbaikan produk, dan di akhiri dengan tahap implementasi. Pada tahap perijinan peneliti melakukan proses perijinan mulai dari Dinas Pendidikan Kabupaten Pati, UPT kecamatan Kota, UPT kecamatan Margorejo dan UPT kecamatan Juwana. Kemudian peneliti melanjutkan memimta ijin penelitian ke SDN Blaru 02, SDN Sukoharjo 01 dan SDN Bakaran Wetan 01.

Tahap analisis kebutuhan meliputi menganalisis literature dan referensi yang dibutuhkan, membuat rancangan perangkat pembelajaran, menganalisis kebudayaan lokal masyarakat kabupaten Pati sesuai lokasi masing-masing sekolah. Kecamatan Kota meliputi makanan khas soto kemiri, nasi gandul, dan petis runting. Kecamatan Margorejo meliputi wisata 
religi makam, dan perpustakaan daerah. Kecamatan Juwana meliputi TPI, Industri batik bakaran, industri kuningan, dan ketoprak. Selanjutnya peneliti merancang pengembangan media berbasis budaya lokal masyarakat kabupaten Pati, merancang instrument dan mendesain pembelajaran tematik integrative.

\begin{tabular}{|c|c|c|}
\hline $\begin{array}{c}\text { STUDI } \\
\text { PENDAHULUAN }\end{array}$ & $\rightarrow \begin{array}{c}\text { TAHAP } \\
\text { PENGEMBANGAN } \\
\text { MEDIA }\end{array}$ & $\begin{array}{c}\text { TAHAP VALIDASI } \\
\rightarrow \quad \text { MEDIA }\end{array}$ \\
\hline $\begin{array}{l}\text { 1. Studi Pustaka: teori } \\
\text { dan hasil penelitian } \\
\text { terdahulu. } \\
\text { 2. Studi lapangan: } \\
\text { persepsi guru untuk } \\
\text { pembelajaran } \\
\text { tematik integratif, } \\
\text { kondisi dan pola } \\
\text { pembelajaran guru, } \\
\text { pola belajar siswa, } \\
\text { sarana prasaran, } \\
\text { 3. Analisi budaya lokal } \\
\text { masyarakat di } \\
\text { lingkungan sekolah } \\
\text { dasar masing-masing } \\
\text { kecamatan }\end{array}$ & Media awal & $\begin{array}{r}\text { Implementasi media } \\
\text { dalam pembelajaran } \\
\text { Media teruji }\end{array}$ \\
\hline
\end{tabular}

\section{Gambar 1. Prosedur Penelitian dan Pengembangan}

Pada tahap pengembangan produk yang peneliti lakukan sebagai berikut menyusun perangkat pembelajaran tematik integratif dengan pendekatan scientific berbasis budaya lokal masyarakat kabupaten Pati. Perangkat pembelajaran yang dibuat adalah silabus dan RPP. Peneliti memulai dengan menyusun KI dan KD dari tema Berbagai Pekerjaan dan sub tema Jenis-jenis Pekerjaan pada pembelajaran ke pertama dengan muatan IPA, Bahasa Indonesia, dan IPS. Materi pada muatan IPA meliputi menjelaskan sumber daya alam di suatu daerah dan menghubungkannya dengan jenis-jenis pekerjaan yang ada. Sedangkan materi pada muatan Bahasa Indonesia meliput mengolah informasi tentang proses pembuatan batik bakaran. Materi pada muatan IPS meliputi mengidentifikasi sumber batik bakaran, mengidentifikasi keberadaan jenis-jenis pekerjaan serta hubungannya dengan kondisi geografis, dan menjelaskan proses pembuatan batik bakaran. Berikutnya Peneliti menganalisis budaya lokal masyarakat Pati kota: makanan khas gandul, soto kemiri dan petis runting. Margorejo: wisata religi dan taman baca desa. Juwana: TPI, industry kuningan, industri batik dan ketoprak.

Peneliti menyusun LKS berbasis budaya lokal masyarakat kabupaten Pati, mengembangan media pembelajaran berbasis budaya lokal masyarakat kabupaten Pati sesuai wilayah masing-masing dan menyusun instrumen lembar aktivitas siswa yang 
digunakan untuk memandu siswa dalam kegiatan pembelajaran dari awal sampai akhir. Lembar aktivitas guru dalam pembelajaran yang digunakan untuk mengamati keterlaksanaan dan pengelolaan pembelajaran yang dilakukan peneliti. Selanjutnya peneliti menyusun soal tes evaluasi yang digunakan untuk mengukur kemampuan kognitif siswa setelah diberikan pembelajaran, menyusun angket respon guru dan angket respon siswa.
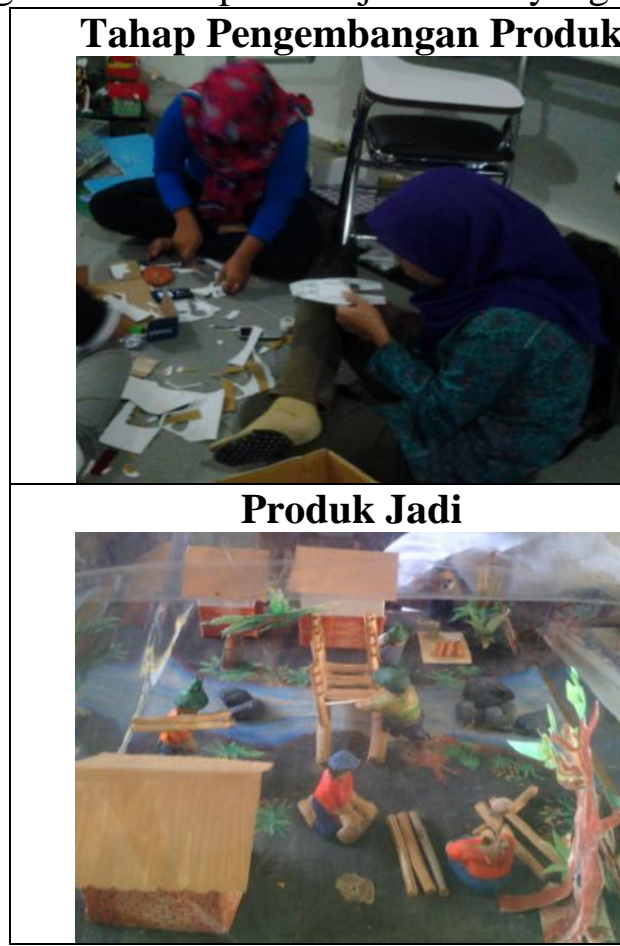

Produk Jadi

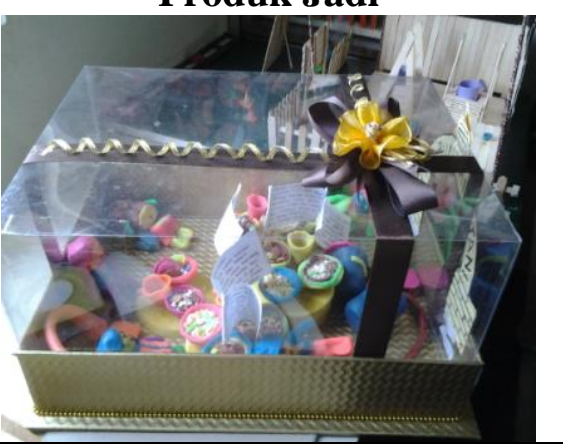

Implementasi pembelajaran

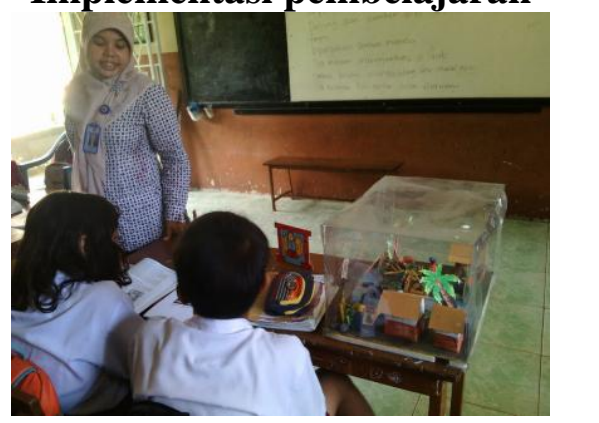

Gambar 2. Produksi Media-Implementasi

Peneliti selanjutnya melakukan uji coba dan melakukan perbaikan. Terakhir peneliti mengimplementasikan dan didapatkan hasil 1) lembar aktivitas guru, pembelajaran sudah berjalan dengan baik sesuai rencana pembelajaran. Suasana kelas sangat kondusif, dan terkendali sehingga siswa antusias dan aktif mulai dari awal pembelajaran sampai akhir. Skor ratarata aktivitas guru sebesar 4,12. 2) Hasil aktivitas siswa menunjukkan bahwa siswa sangat senang di ajak bernyanyi, mengamati, menganalisis dari lagu, gambar sampai media yang digunakan. Skor rata-rata aktivitas siswa sebesar 4,2. 3) Hasil evaluasi siswa rata-rata sebesar 79,8 dengan kriteria ketuntasan sebesar 68,5. 4) Angket respon siswa terhadap pembelajaran menunjukkan skor 4,3. Siswa mengaku senang dengan pembelajaran. Siswa senang mendapat pengalaman dari gambar melihat media sampai menganalisis media yang digunakan. 5) Angket respon guru terhadap pembelajaran dengan menggunakan media berbasis budaya lokal menunjukkan skor 4,24. Guru sangat tertarik memberikan pembelajaran dengan mengangkat budaya lokal, ternyata siswa sangat antusias dan mengena.

Hasil penelitian tersebut menunjukkan bahwa sebagai seorang pendidik perlu untuk menciptakan pembelajaran yang bermakna. Pembelajaran dengan mengangkat budaya lokal daerah, memberikan inovasi pembelajaran yaitu dengan pendekatan saintifik. Menurut Fauziah (2013) pendekatan saintifik mengajak siswa langsung dalam menginferensi masalah 
yang ada dalam bentuk rumusan masalah dan hipotesis, rasa peduli terhadap lingkungan, rasa ingin tahu dan gemar membaca.

Berdasarkan uraian diatas, terlihat betapa pentingnya pendekatan saintifik berbasis budaya lokal di Pati bisa digunakan dalam pembelajaran dikelas, karena pendekatan saintifik dapat mengembangkan berbagai skill seperti keterampilan berpikir kritis (critical thinking skill), keterampilan berkomunikasi (communication skill), keterampilan melakukan kerja sama dan penyelidikan (research and collaboration skill) dan perilaku berkarakter, karena pengalaman belajar yang diberikan dapat memenuhi tujuan pendidikan dan bermanfaat bagi pemecahan masalah dan kehidupan nyata.

\section{KESIMPULAN}

Berdasarkan paparan data dan pembahasan yang telah disajikan pada bab sebelumnya, maka dapat dikemukakan kesimpulan akhir sebagai jawaban atas permasalahan penelitian adalah pembelajan berjalan sangat efektif dengan media pembelajaran tematik integrative berbasis budaya lokal masyarakat Pati dengan pendekatan scientific. Berdasarkan kesimpulan tersebut diberikan saran bahwa perlu meningkatkan pengembangan media pembelajaran untuk setiap daerah dengan mengangkat budaya masingmasing daerah agar pembelajaran dapat bermakna serta budaya daerah dapat dilestarikan.

\section{DAFTAR PUSTAKA}

Alexon, dkk. 2010. Pengembangan Model Pembelajaran Terpadu Berbasis Budaya Untuk
Meningkatkan Apresiasi Siswa Terhadap Budaya Lokal. Cakrawala Pendidikan. Juni, Th. XXIX, No.2.

Arsyad, A. 2006. Media Pembelajaran. Jakarta: Raja Grafindo Persada.

Borg, W. R. and Gall, M. D. 1989. Educational Research: An Introduction. New York: Longman

Carin, A.A. \& Sund, R.B. 1975. Teaching Science trough Discovery, $3^{\text {rd }} E d$. Columbus: Charles E. Merrill Publishing Company.

Emzir, Prof. Dr. M.Pd,. 2011. Metodologi Penelitian Pendidikan Kuantitatif dan Kualitatif. Jakarta: Rajawali Pers.

Fauziah. 2013. Pendekatan Pembelajaran. Jakarta: Erlangga.

Green, M. and McNeese, N.M. 2007. "Using Edutainment Software to Enhance Online Learning." International Journal on Elearning, 6: 5-16

Gering Supriyadi. 2003. Budaya Kerja Pegawai Negeri Sipil. Lembaga Administrasi Negara. Jakarta.

Nur, M. \& Wikandari, P.R. 2000. Pengajaran Berpusat Kepada Siswa Dan Pendekatan Konstruktivis Dalam Pengajaran. Surabaya : Universitas Negeri Surabaya University Press.

Rusman. 2010. Model-Model Pembelajaran: Mengembangkan Profesionalisme Guru. Rajawali Press (Hlm.254).

Sutarno. 2004. Pembelajaran Berbasis Budaya. Jakarta: Raja Grafindo Persada 